\author{
Marquette University \\ e-Publications@Marquette
}

$12-2015$

\title{
Biochar from Pyrolysis of Biosolids for Nutrient Adsorption and Turfgrass Cultivation
}

Daniel Elliott Carey

Marquette University

Patrick J. McNamara

Marquette University, patrick.mcnamara@marquette.edu

Daniel Zitomer

Marquette University, daniel.zitomer@marquette.edu

Follow this and additional works at: https://epublications.marquette.edu/civengin_fac

Part of the Civil Engineering Commons

\section{Recommended Citation}

Carey, Daniel Elliott; McNamara, Patrick J.; and Zitomer, Daniel, "Biochar from Pyrolysis of Biosolids for Nutrient Adsorption and Turfgrass Cultivation" (2015). Civil and Environmental Engineering Faculty Research and Publications. 127.

https://epublications.marquette.edu/civengin_fac/127 


\title{
Biochar from Pyrolysis of Biosolids for Nutrient Adsorption and Turfgrass Cultivation
}

\author{
D. E. Carey ${ }^{1}$, P. J. McNamara ${ }^{1}$, D. H. Zitomer ${ }^{1 *}$
}

\begin{abstract}
At water resource recovery facilities, nutrient removal is often required and energy recovery is an ever-increasing goal. Pyrolysis may be a sustainable process for handling wastewater biosolids because energy can be recovered in the py-gas and py-oil. Additionally, the biochar produced has value as a soil conditioner. The objective of this work was to determine if biochar could be used to adsorb ammonia from biosolids filtrate and subsequently be applied as a soil conditioner to improve grass growth. The maximum carrying capacity of base modified biochar for $\mathrm{NH}_{3}-\mathrm{N}$ was $5.3 \mathrm{mg} / \mathrm{g}$. Biochar containing adsorbed ammonium and potassium was applied to laboratory planters simulating golf course putting greens to cultivate Kentucky bluegrass. Planters that contained nutrient-laden biochar proliferated at a statistically higher rate than planters that contained biosolids, unmodified biochar, peat, or no additive. Nutrient-laden biochar performed as well as commercial inorganic fertilizer with no statistical difference in growth rates. Biochar from digested biosolids successfully immobilized $\mathrm{NH}_{3}-\mathrm{N}$ from wastewater and served as a beneficial soil amendment. This process offers a means to recover and recycle nutrients from water resource recovery facilities. Water Environ. Res., 87, 2098 (2015).
\end{abstract}

KEYWORDS: biochar, adsorption, ammonia, ammonium, pyrolysis, biosolids, nutrient removal, recycling.

doi:10.2175/106143015X14362865227391

\section{Introduction}

Nitrogen $(\mathrm{N})$ and phosphorus $(\mathrm{P})$ removal from wastewater is often required to maintain the integrity of receiving waters. Therefore, wastewater treatment typically incorporates nutrient removal (U.S. EPA, 1998). Conventional $\mathrm{N}$ and phosphorus removal requires substantial energy for aeration and mixing, as well as additional resources (e.g., carbon sources, media, land) (Metcalf and Eddy et al., 2003). Currently in wastewater management, an emphasis is being placed on implementing more sustainable systems that reduce energy usage (McCarty et al., 2011).

In addition to reducing energy demand, sustainable wastewater management scenarios involve reclaiming nitrogen and phosphorus as well as recovering energy from biosolids (Mayer et al., 2013; Verstraete et al., 2009). Nitrogen, phosphorus, and potassium (K) recycled from wastewater can be used in agriculture as they are essential plant nutrients and found in most fertilizers. Although nutrients within conventionally stabilized biosolids can be used for agronomy by land

\footnotetext{
${ }^{1}$ Department of Civil, Construction and Environmental Engineering, Marquette University, P.O. Box 1881, Milwaukee, Wisconsin 53201, USA.

*E-mail: daniel.zitomer@marquette.edu.
}

application of biosolids, limited opportunities exist to recycle nutrients from the aqueous phase in wastewater treatment. The most common method for removing nitrogen from wastewater is nitrification/denitrification (Metcalf and Eddy et al., 2003). This process is highly effective at removing nitrogen; however the nitrogen is converted to $\mathrm{N}_{2}$ gas and is not available to be recovered. Adsorption of nutrients from the aqueous phase has been investigated; however exchange media, such as clinoptilolite, polymeric adsorption resins, and hybrid exchange media can be expensive and the regeneration of the media can be difficult (Mayer et al., 2013). More extensive recovery of phosphorus and potassium may soon be required as a result of the prodigious rate these nonrenewable resources are being exploited (Ma et al., 2010; Vlek et al., 1997). The recycling of potassium could be especially advantageous in areas that rely on importing potash for agriculture (Xu et al., 2012).

Pyrolysis for Energy Recovery and Biochar Production. Biochar, a potentially inexpensive product of biosolids pyrolysis, may be a practical adsorbent for ammonia-N. Pyrolysis of biosolids could contribute to a sustainable wastewater process by reclaiming biosolids energy in the form of py-gas and py-oil and producing a valuable biochar adsorbent that can be used as a soil amendment (McNamara et al., 2014; Van Zwieten et al., 2010). Pyrolysis is an abiotic process in which biomass is heated to greater than $300{ }^{\circ} \mathrm{C}$ and thermally degraded under anaerobic conditions (Inguanzo et al., 2002). Three products can be recovered from pyrolysis: biochar (a solid end-product similar to charcoal), py-oil (a liquid end-product that condenses when the pyrolysis products are cooled to ambient temperature, similar to crude oil), and py-gas (a gas end-product that does not condense at ambient temperature, similar to natural gas). The py-gas fraction is readily available as an energy source as it is mainly $\mathrm{CH}_{4}, \mathrm{H}_{2}$, and $\mathrm{CO}$ (Furness et al., 2000) with a heating value of approximately 5000 to $20000 \mathrm{KJ} / \mathrm{kg}$-gas, depending on pyrolysis temperature (McNamara et al., 2014). If the hot gas emitted from pyrolysis is not cooled, but remains at a high temperature, then the py-oil remains in the gas phase with the py-gas, and this blend could be directly combusted for energy recovery.

Pyrolysis of dried biosolids has been reported to produce enough energy to be self-sustaining and produce excess energy if the pyrolysis temperature is above $450{ }^{\circ} \mathrm{C}$ (Wang et al., 2012). After accounting for energy required for the pyrolysis reaction (enthalpy of pyrolysis), additional energy may be available in the py-gas and py-oil to for biosolids drying and renewable heat or electricity generation (McNamara et al., 2014). Py-oil has potential to be condensed and refined into industrial chemicals or blended and refined with petroleum feedstocks (Volli and Singh, 2012). Biochar uses include combustion as a fuel, addition 
to soil as a supplement, or use in novel applications, such as adsorption (Gao and Wu, 2011; Liu et al., 2014; Zimmerman et al., 2011).

Biochar has been created from many organic feedstocks including wood, bamboo, and agricultural byproducts such as corn stover, peanut hulls, and pressed sugar cane (Yao et al., 2012). Full-scale pyrolysis of wood waste has been demonstrated (Phoenix Energy, 2014). Municipal wastewater biosolids pyrolysis has been investigated for more than 30 years, initially as a method to produce higher quality air emissions when compared to combustion of biosolids (Kaminsky at al., 1982; Kasakura and Hiraoka, 1982; Kasakura et al., 1981). Pyrolysis temperature greatly affects the ratio of end-products, with higher temperatures increasing py-gas yield, lower temperatures increasing biochar yield, and the fraction of py-oil remains relatively constant (Inguanzo et al., 2002). The ratio of end-products can greatly affect the value recovered. For example, biosolids-derived biochar has potential to be a high-value end product (Liu et al., 2014). The economics of pyrolysis are greatly impacted by the value of the recovered end-products.

Biochar has practical benefits and can be an effective product for sustainable environmental improvement. Biochar is valuable as a soil amendment and has been shown to improve soil quality while removing carbon from the atmosphere. Biochar amendment of soil encourages development of beneficial microbial communities and activity, helps retain nutrients for enhanced plant growth, and prevent water runoff (Brockhoff et al., 2010; Lehmann, 2007). Although the mechanisms have not been fully elucidated, biochar addition to soil often results in higher crop yields and decreased fertilizer requirements (Gaunt and Lehmann, 2008; Schulz and Glaser, 2012). Furthermore, biochar carbon is relatively stable and resistant to biochemical conversion to $\mathrm{CO}_{2}$. Therefore, biochar sequesters carbon for long periods and its production and land application may help mitigate climate change (Woolf et al., 2010). Use of pyrolysis gas and oil fuels from biochar production coupled with prudent use of biochar may be tools for carbon-neutral or carbon-negative fuel production (Lehmann, 2007).

Biochar as an Adsorbent. Biochar is an amorphous carbon matrix similar to charcoal and can be used as a sorbent much like activated carbon (Zhang et al., 2013). Biochar exhibits varying degrees of adsorptive capacity for pesticides, explosives, polyaromatic hydrocarbons, radionuclides, heavy metals, ammonium, nitrate, phosphate, or other groundwater contaminants (Kalyak et al., 2013; Jiang et al., 2012; Yao et al., 2012; Zhang et al., 2013; Zheng et al., 2010). Biochars produced from different feed materials have been shown to have varying adsorptive capacity resulting from variations in surface chemistry (Yao et al., 2012). Additionally, different pyrolysis temperatures and production methods of a single feedstock result in biochars with different properties. Prediction of the adsorptive capacity of a specific biochar for a specific chemical $a$ priori is not currently possible due to the complex surface chemistry resulting from high temperatures of pyrolysis, differences in feedstock properties, and other factors.

Biochar derived from various feedstocks has been demonstrated to adsorb nitrogen species. Yao et al. (2012) compared ammonium adsorption/leaching from biochars produced using four different feedstocks (sugar cane, pepperwood, bamboo, and peanut hulls); some biochar adsorbed $0.75 \mathrm{mg} / \mathrm{g}$ of ammonium, whereas others released up to $1 \mathrm{mg} / \mathrm{g}$. The adsorptive capacity of biochar for ammonia varies widely among studies depending on pyrolysis scheme. For example, bamboo biochar either adsorbed up to $9 \mathrm{mg} / \mathrm{g}$ of ammonium or released as much as $0.5 \mathrm{mg} / \mathrm{g}$ of ammonium depending on pyrolysis temperature (Asada et al., 2006; Yao et al., 2012). Previous work has shown that biochar can adsorb and retain $\mathrm{NH}_{3}-\mathrm{N}$ without significant loss via volatilization to the atmosphere (Taghizaheh-Toosi et al., 2012).

Biochar can be modified by physical or chemical alterations, which affect surface chemistry or pore structure to improve adsorptive capacity for a target compound (Azargohar and Dalai, 2008). Acid or base treatment has been used to etch, increase surface area, and alter surface chemistry (Rambabu et al., 2013). Further, high temperature steam treatment can alter surface structure (Bansode et al., 2003). Modification with $\mathrm{H}_{2} \mathrm{SO}_{4}$ has been shown to increase the capacity of bamboo-derived biochar to immobilize ammonia in aqueous solutions, but no research reports were found to describe how biosolid-derived biochar can be altered to remove ammonia from wastewater streams (Asada et al., 2006). Modification of biochar with acid or base has been shown to alter the adsorptive capacity for other target chemicals (Azargohar and Dalai, 2008). The use of biochar as a sorbent to remove ammonia could be beneficial because the resulting biochar could be used as a nitrogen-rich soil amendment. The use of wastewater nutrient-enhanced biochar, that is, biochar that has been used to sorb ammonia from wastewater, on plant growth has not been well characterized.

Research Objectives. The objectives of this study were to determine (1) the effect of modifying biochar on the biochar sorption of ammonia and (2) the effect of biochar and biochar-N on turfgrass growth. Biochar and base modified biochar (both derived from wastewater biosolids) were used to adsorb $\mathrm{NH}_{3}-\mathrm{N}$ in filtrate from wastewater biosolids dewatering. The biochar with adsorbed $\mathrm{NH}_{3}-\mathrm{N}$ was then used as a soil amendment for turfgrass cultivation. Different biochar activation techniques were studied, including acid and base treatment, in an effort to increase $\mathrm{NH}_{3}-\mathrm{N}$ adsorption from anaerobic digester filtrate.

\section{Methods}

Biosolids Pyrolysis and Washed Biochar. Dried wastewater biosolids were obtained from a municipal water reclamation facility (Milorganite, Jones Island Water Reclamation Facility, Oak Creek, Wisconsin). The biosolids material was a blend of anaerobically digested primary solids and undigested waste activated sludge. For pyrolysis, approximately $100 \mathrm{~g}$ of dried biosolids were placed in a $250-\mathrm{mL}$ Erlenmeyer flask. Immediately before pyrolysis, the flask was purged with $\mathrm{CO}_{2}$ at $5 \mathrm{~L} / \mathrm{min}$ for 5 minutes. Aluminum foil was placed over the top of the flask, and the flask was placed in a muffle furnace at $450{ }^{\circ} \mathrm{C}$ for 1.5 hours. Biochar was allowed to cool to ambient temperature inside the furnace following the experiment. Cooled biochar (200 g collected over several pyrolysis runs) was washed 3 times by shaking with $1 \mathrm{~L}$ of distilled deionized water for 5 minutes and decanting the water. Washed biochar was dried in a $105{ }^{\circ} \mathrm{C}$ oven for 12 hours and stored under desiccation at room temperature until use.

Base Modified Biochar. For base modification, $1 \mathrm{~kg}$ of washed biochar was added to $2.5 \mathrm{~L}$ of $1 \mathrm{~N} \mathrm{KOH}$ solution for 1.5 hours on a shaker table at room temperature. Biochar was subsequently removed from the solution and rinsed 10 times with $3.8 \mathrm{~L}$ of distilled deionized water. Rinsed biochar was transferred to a metal pan and dried in an oven at $105^{\circ} \mathrm{C}$ for 12 
hours. Base modified biochar was stored under desiccation at room temperature before analysis or use.

Adsorption Studies. Washed and base modified biochars were used to develop $\mathrm{NH}_{3}-\mathrm{N}$ adsorption isotherms to identify the most promising adsorbent to use for turfgrass studies. One gram of biochar was added to several 100-mL glass bottles with screw cap closure; $100 \mathrm{~mL}$ of a different aqueous $\mathrm{NH}_{3}-\mathrm{N}$ solution, made from $\mathrm{NH}_{4} \mathrm{Cl}$, was added to each bottle. Initial aqueous concentrations of $\mathrm{NH}_{3}-\mathrm{N}$ used were $0,0.66,6.6,66$, $160,330,490$, and $660 \mathrm{mg} / \mathrm{L}$. The samples were left on a shaker table for 24 hours. The mass of $\mathrm{NH}_{3}-\mathrm{N}$ adsorbed was calculated by determining the difference between the initial and final $\mathrm{NH}_{3}-\mathrm{N}$ concentration after 24 hours in the closed bottles. Standards were also run in closed screw cap bottles with the same aqueous and headspace volumes as the test bottles to account for any minor losses (e.g., volatilization or adsorption to the glass). The $\mathrm{pH}$ was measured at the beginning and end of the batch adsorption tests, and no significant change in $\mathrm{pH}$ was observed. Isotherms were fit using linear, Fruendlich and Langmuir models. A linear isotherm was fit to the data using the following model:

$$
q_{e}=k C
$$

where $q_{e}(\mathrm{mg} / \mathrm{g})$ is the equilibrium concentration of $\mathrm{NH}_{3}-\mathrm{N}$ sorbed to biochar, $C(\mathrm{mg} / \mathrm{L})$ is the equilibrium concentration of $\mathrm{NH}_{3}-\mathrm{N}$ in the bulk solution, and $k(\mathrm{~L} / \mathrm{g})$ is the linear isotherm adsorption coefficient. For comparison, a commercial clinoptilolite ion exchange mineral used for ammonia adsorption (Zeolite ZS403H $14 \times 40 \mathrm{MESH}$, St. Cloud, Winston, New Mexico) and activated carbon $(10 \times 30$ mesh GAC, MRX-M, Calgon Carbon Corp., Pittsburg, Pennsylvania) were also used as adsorbents in deionized water solutions of $660 \mathrm{mg} / \mathrm{L}$ of $\mathrm{NH}_{3}-\mathrm{N}$ and with filtrate from biosolids dewatering.

Preparation of Biochar for Turfgrass Studies. The $\mathrm{NH}_{3}-\mathrm{N}$ carrying capacity for base modified biochar was higher than washed biochar; therefore modified biochar was chosen for turfgrass growth studies. Modified biochar was contacted with filtrate from belt filter press biosolids dewatering collected at a water reclamation facility (Jones Island Water Reclamation Facility, Oak Creek, Wisconsin). The belt filter press dewatered a mix of anaerobically digested primary sludge and waste activated sludge. The filtrate $\mathrm{NH}_{3}-\mathrm{N}$ concentration was approximately 32 $\mathrm{mg} / \mathrm{L}$. Modified biochar was mixed with filtrate and was set on a shaker table to equilibrate for 12 hours in a closed container with no headspace. Immobilized $\mathrm{NH}_{3}-\mathrm{N}$ was quantified by measuring ammonia concentration of the filtrate before the addition of biochar and after equilibration. The resulting nutrient-laden biochar was referred to as "biochar-N".

Turfgrass Growth. Planter studies were conducted to compare the effectiveness of unmodified biochar and biochar$\mathrm{N}$ as fertilizers and soil amendments for turfgrass growth. Evaluations were made based on the growth rate of Kentucky bluegrass using planters simulating golf putting greens in a controlled greenhouse. The goal of this experiment was to determine if biochar or biochar- $\mathrm{N}$ have plant-available nutrients and stimulate turfgrass growth; other treatments used for comparison within this study may not have equivalent availabilities of nitrogen, phosphorus, potassium, or micronutrients.
Polyvinylchloride (PVC) planters were constructed using 10.2$\mathrm{cm}$ (4-in.) diameter pipe at a length of $38 \mathrm{~cm}$. Each planter bottom was fit with a watertight cap and an effluent tube that could be open or closed. At the bottom of the planter, a $5-\mathrm{cm}$ base of pebble stone was laid with a piece of landscaping fabric above it. Atop the fabric, dry, nutrient-free sand, typically used as a base for golf course putting greens (Mason Sand, Faulks Construction Bros, Inc., Waupaca, Wisconsin) was used as the primary media.

Different media with various soil amendments and fertilizers were prepared and consisted of the following treatments with sand: (1) only sand, (2) biochar, (3) biochar-N, (4) peat, (5) inorganic fertilizer, (6) biosolids, (7) biochar + inorganic fertilizer, and (8) biochar- $\mathrm{N}+$ inorganic fertilizer. Previous literature suggested a $10 \% \mathrm{v} / \mathrm{v}$ application of biochar in soil can produce favorable effects (Revell et al., 2012; Van Zwieten et al., 2010). The nitrogen content of biochar- $\mathrm{N}$ was more similar to that of peat rather than fertilizer; thus biochar and peat (Sphagnum Peat Moss, Premier, Canada) were both added at 10\% v/v (165 g biochar/planter and $30 \mathrm{~g}$ peat/planter). Dried biosolids fertilizer (Milorganite) and inorganic fertilizer (Shake'n Feed 10-10-10, Miracle Grow, Scotts) were applied at the manufacturers' recommended rates of $36 \mathrm{lb}$ Milorganite per $2500 \mathrm{ft}^{2}$ (approximately $570 \mathrm{mg}$ per planter) and $4.5 \mathrm{lb}$ Miracle Grow per $135 \mathrm{ft}^{2}$ (approximately $1.3 \mathrm{~g}$ per planter). Approximately $30.5 \mathrm{~cm}$ (12 in.) of thoroughly mixed sand and soil amendments were applied to each planter; fertilizers were applied to the top of the planters with the seed. Controls were used that did not contain any Kentucky bluegrass seed.

Gravitational water holding capacity (GW, $[\mathrm{kg} / \mathrm{kg}]$ ) for each type of soil was determined; GW was later used to calculate the amount of water needed for daily watering. GW is defined as the mass of water held by the soil between saturation and field capacity; field capacity refers to the mass of water the soil can retain after excess water has drained away. Briefly, GW was measured by constructing a planter with a known mass of media $(M,[\mathrm{~kg}])$. The planter was then saturated with water by adding surplus water and allowing the planter to drain for 1 hour; the total planter weight was measured with the water-saturated soil $\left(P_{\mathrm{o}},[\mathrm{kg}]\right)$. The planters were then covered with a fitted plastic lid and the effluent tube was left open allowing the planter to drain further. The planter was then weighed after excess water had drained over 72 hours $(P,[\mathrm{~kg}])$. The GW was then calculated as the mass of water that drained from saturated soil over 72 hours,

$$
G W=\frac{P_{o}-P}{M}
$$

Each planter was sewn with the recommended application rate of Kentucky bluegrass Mix Grass Seed (Turf Builder, Kentucky Bluegrass Mix, Scotts) at the recommended application rate of $4.5 \mathrm{lbs}$ seed mix/1000 $\mathrm{ft}^{2}$ (178 $\mathrm{mg}$ per planter). With a known mass of soil in each planter, dechlorinated tap water was added to coincide with $80 \%$ of the field capacity. Tap water was dechlorinated by placing it in a container exposed to the atmosphere for 24 hours before use. Each day thereafter, the planter was placed on a scale and dechlorinated tap water was added to bring the planters' total mass up to $80 \%$ of the GW. Planters were maintained in a greenhouse. The air temperature was between 21 and $32{ }^{\circ} \mathrm{C}$. The planters were maintained for 12 weeks. 


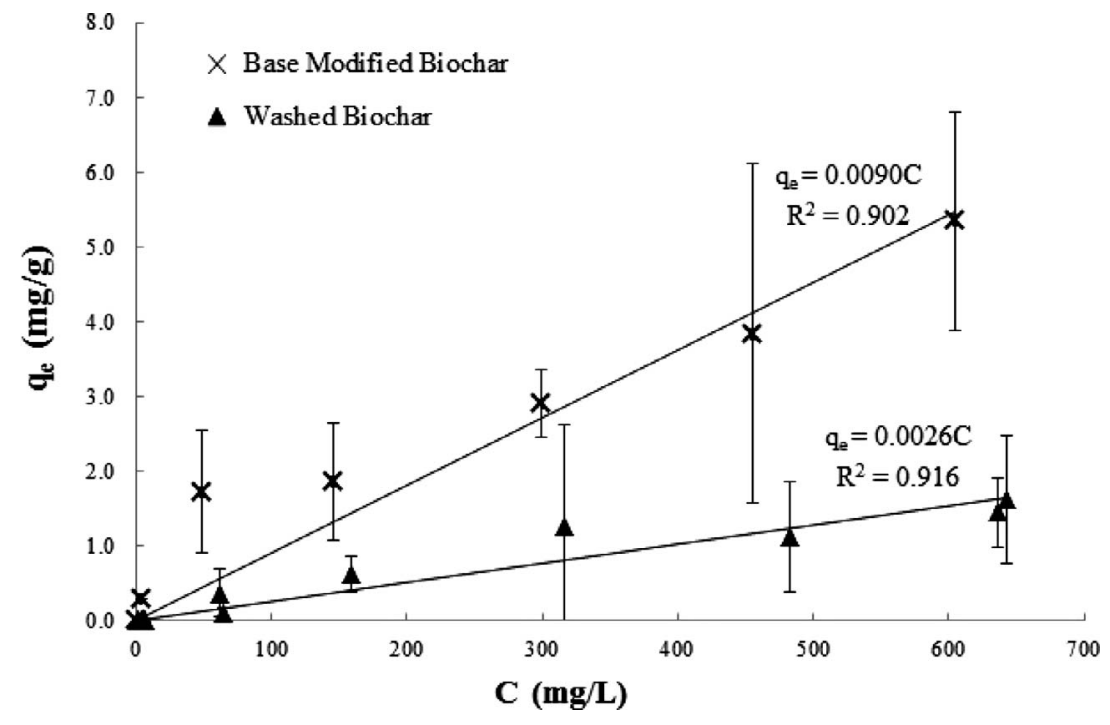

Figure 1-Linear adsorption isotherms of $\mathrm{NH}_{3}-\mathrm{N}$ sorption onto biochar, where $\mathrm{x}$-axis represents (mg $\left.\mathrm{NH}_{3}-\mathrm{N}\right) / \mathrm{g}$ biochar) and y-axis represents the equilibrium aqueous concentration of $\mathrm{NH}_{3}-\mathrm{N}$. Each data point represents 3 separate tests and error bars represent standard deviation.

The grass was clipped to $2.5 \mathrm{~cm}$ ( 1 in.) by hand every week. Grass germination began from 3 to 4 weeks after seeding. The first grass clippings were collected at day 35 and subsequently collected approximately every 7 days. Clippings from each planter were collected and weighed to determine the effect of the various soil amendments on plant growth.

Other Analyses. $\mathrm{NH}_{3}-\mathrm{N}$ in aqueous solutions was measured using the phenol colorimetric method for ammonia and ammonium detection (APHA et al., 1995). Biochar surface area was measured using a Brunauer-Emmett-Teller (BET) surface analysis instrument (NOVA 4200e, Quantachrome instruments, Boynton Beach, Florida). The carbon, hydrogen, nitrogen, and sulfur contents of biosolids and biochar were determined using an ultimate analysis instrument (Vario Micro Cube, Elementar, Hanau, Germany) and the remaining oxygen content was calculated after ash testing $(\mathrm{O} \%=100 \%-\mathrm{C} \%-\mathrm{H} \%-\mathrm{N} \%-$ $\mathrm{S} \%$ - Ash\%). Metals were measured by ICP-OES/MS after nitric acid extraction. Briefly, $0.5 \mathrm{~g}$ of sample was combined with $5 \mathrm{~mL}$ of concentrated nitric acid in a 50-mL Folin tube. The mixture was heated to 120 to $130{ }^{\circ} \mathrm{C}$ for 12 to 14 hours. The sample was diluted to $50 \mathrm{~mL}$, then further diluted in a 1:1 ratio with deionized water to measure major and minor leachable components with ICP-OES/MS (IRIS Advantage, Thermo Jarrell Ash, Franklin, Massachusetts). Plant available nitrate and ammonia in solids (in soil amendments and biochar) were quantified by flow injection. Briefly, $1.5 \mathrm{~g}$ of samples was shaken with $15 \mathrm{~mL}$ of $2 \mathrm{~N} \mathrm{KCl}$ solution for 15 minutes and nitrate as well as ammonia concentrations were determined in solution by flow injection (Quickchem 8000, Lachat, Loveland, Colorado). Biochar samples were screened for possible polycyclic aromatic hydrocarbons (PAHs) using spectrophotometric methods after solvent extraction (Touraud et al., 1998). Briefly, approximately $3.6 \mathrm{~g}$ of biochar were placed in an accelerated solvent extraction system (ASE Dionex 350, Thermo Scientific, Sunnyvale, California) and extracted with approximately $20 \mathrm{~mL}$ of methanol at $60{ }^{\circ} \mathrm{C}$ over two 5 -minute cycles. The extract was diluted $10 \times$ with methanol and the concentration of PAHs in the diluted extract was estimated using a spectrophotometer at a wavelength of $256 \mathrm{~nm}$ (Genesys $10 \mathrm{UV}$, Thermo Electron Corp., Sunnyvale, Caifornia).

Statistical Analysis. ANOVA, Fischer's least square difference, student $t$-tests, and linear regressions were performed using Microsoft Excel 2010 and GraphPad Prism v. 6.04. Linear isotherms were fit with the Microsoft Excel tool. Error bars in figures represent 1 standard deviation unless otherwise indicated.

\section{Results and Discussion}

Ammonia Immobilization on Biochar. Both washed and base modified biochars adsorbed $\mathrm{NH}_{3}-\mathrm{N}$, and a linear isotherm model fit the data over the range of $\mathrm{NH}_{3}-\mathrm{N}$ concentrations used (Figure 1). Base modified biochar demonstrated statistically higher $\mathrm{NH}_{3}-\mathrm{N}$ adsorption as indicated by a partition coefficient of $9.0 \times 10^{-3} \mathrm{~L} / \mathrm{g}$ compared to the washed biochar value of 2.6 $\times 10^{-3} \mathrm{~L} / \mathrm{g}$. The coefficients of determination $\left(R^{2}\right)$ for both isotherms were $>0.9$, indicating the model fit well. Washed and base modified biochar isotherm slopes ( $k$ values) were significantly different $(p<0.0001)$. The higher sorptive capacity of base modified biochar ostensibly was the result of its higher specific surface area of $19 \mathrm{~m}^{2} / \mathrm{g}$ in comparison to $10 \mathrm{~m}^{2} / \mathrm{g}$ for washed biochar. Surface chemistry changes resulting from base modification may have also contributed to the higher adsorptive capacity of the modified biochar (Rambabu et al., 2013).

Two commercial adsorbents (clinoptilolite and activated carbon) were used for comparison to base modified biochar, and were contacted with either an ammonium chloride solution $\left(660 \mathrm{mg} / \mathrm{L} \mathrm{NH}_{3}-\mathrm{N}\right)$ or filtrate from biosolids thickening $(32 \mathrm{mg} /$ $\mathrm{L} \mathrm{NH}_{3}-\mathrm{N}$ ) to determine $\mathrm{NH}_{3}-\mathrm{N}$ adsorption. The modified biochar demonstrated higher $\mathrm{NH}_{3}-\mathrm{N}$ adsorption than activated carbon and lower adsorption than clinoptilolite. In the biosolids filtrate, the modified biochar immobilized $0.8 \mathrm{mg} \mathrm{NH}-\mathrm{N} / \mathrm{g}$, which was $50 \%$ lower than that of clinoptilolite $(1.6 \mathrm{mg} / \mathrm{g})$, but was $170 \%$ higher than activated carbon $(0.3 \mathrm{mg} / \mathrm{g})$. In the $\mathrm{NH}_{4} \mathrm{Cl}$ solution, the modified biochar adsorbed $5.3 \mathrm{mg} \mathrm{NH}-\mathrm{N} / \mathrm{g}$, while 
Table 1-Extractable major and minor nutrients (mg/kg sample).

\begin{tabular}{|c|c|c|c|c|c|c|}
\hline & Constituent & Biochar-N & Base modified biochar & Biochar & Biosolids (Milorganite) & Peat \\
\hline \multirow[t]{7}{*}{ Major Nutrients } & $\mathrm{NH}_{3}-\mathrm{N}$ & 15 & 13 & 33 & 590 & 11 \\
\hline & $\mathrm{NO}_{3}-\mathrm{N}$ & 0.26 & 0.70 & 0.78 & 2.1 & 19 \\
\hline & $\mathrm{P}$ & 1.4 & 8.9 & 6.2 & 200 & 1.6 \\
\hline & K & 1400 & 600 & 640 & 800 & 3.6 \\
\hline & $\mathrm{Ca}$ & 140 & 34 & 450 & 470 & 46 \\
\hline & $\mathrm{Mg}$ & 290 & 27 & 22 & 240 & 19 \\
\hline & $\mathrm{Na}$ & 490 & 970 & 160 & 400 & 9.6 \\
\hline \multirow[t]{7}{*}{ Minor Nutrients } & $S$ & 380 & 290 & 29 & 500 & 4.3 \\
\hline & $\mathrm{Zn}$ & 8.2 & 3.6 & 0.93 & 2.0 & 0.31 \\
\hline & $\mathrm{B}$ & 0.42 & 0.26 & 0.49 & 0.48 & $<0.02$ \\
\hline & $\mathrm{Mn}$ & 35 & 18 & 3.9 & 7.7 & 2.0 \\
\hline & $\mathrm{Fe}$ & 4.1 & 5.3 & 37 & 52 & 16 \\
\hline & $\mathrm{Cu}$ & 0.80 & 0.25 & 0.31 & 3.1 & 0.20 \\
\hline & $\mathrm{Al}$ & $<0.05$ & $<0.05$ & $<0.05$ & 1.7 & 2.4 \\
\hline
\end{tabular}

activated carbon was able to adsorb $0.5 \mathrm{mg} \mathrm{NH}_{3}-\mathrm{N} / \mathrm{g}$ and

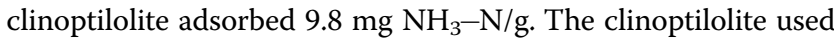
in this study is known to have exchangeable cations, and was therefore expected to have a high affinity for ammonium. Previous studies have shown that activated carbon has a wide range of adsorption capacities for $\mathrm{NH}_{3}-\mathrm{N}$ ranging from $0.5 \mathrm{mg} /$ $\mathrm{g}$ to $17.2 \mathrm{mg} / \mathrm{g}$ under laboratory conditions (Boopathy et al., 2013; Long et al., 2008; Love et al., 2011).

Biochar and Soil Additive Characteristics. Biochar-N provided $2 \mathrm{mg} / \mathrm{kg}$ more available $\mathrm{NH}_{3}-\mathrm{N}$ than the base modified biochar that had not been contacted with filtrate containing $\mathrm{NH}_{3}-\mathrm{N}$ (Table 1). The biochar-N was expected to contain 800 $\mathrm{mg} / \mathrm{kg}$ of total $\mathrm{NH}_{3}-\mathrm{N}$ according to the equilibrium partition coefficient calculations described above. Indeed, the total $\mathrm{NH}_{3}-\mathrm{N}$ adsorbed from the filtrate was approximately $800 \mathrm{mg}$ $\mathrm{NH}_{3}-\mathrm{N} / \mathrm{kg}$ biochar based on the $\mathrm{NH}_{3}-\mathrm{N}$ aqueous concentrations in filtrate measured before and after biochar exposure Therefore, the biochar adsorbed a significant mass of total $\mathrm{NH}_{3}-\mathrm{N}$. However, the available $\mathrm{NH}_{3}-\mathrm{N}$ increase on biochar- $\mathrm{N}$ was only approximately $0.2 \%$ of the total $\mathrm{NH}_{3}-\mathrm{N}$ because some of the $\mathrm{NH}_{3}-\mathrm{N}$ was strongly adsorbed and not readily desorbed under the conditions used to measure the available $\mathrm{NH}_{3}-\mathrm{N}$ fraction. Biochar produced from wood biomass also has been shown to adsorb and retain 550 to $900 \mathrm{mg} \mathrm{NH}-\mathrm{N} / \mathrm{kg}$ biochar, but only 6 to $25 \%$ of the total $\mathrm{NH}_{3}-\mathrm{N}$ was available when biochar was placed in soil (Taghizaheh-Toosi et al., 2012).

In addition to adsorbing nitrogen, the biochar adsorbed potassium from the biomass filtrate. An $800 \mathrm{mg} / \mathrm{kg}$ increase in potassium was observed in biochar- $\mathrm{N}$ relative to base modified biochar with no filtrate contact. Potassium is an essential plant nutrient that can have a positive effect on plant growth. Although potassium was not the focus of this study, it may have affected turfgrass growth. Future research is required to determine the potential of biochar as an adsorbent for potassium.

Dried biosolids and biosolid-derived biochars had similar C:N ratios: 5.8 and 6.1, respectively (Figure 2). Nitrogen within biosolids volatilized in approximately the same ratio as carbon during pyrolysis; organic carbon is known to gasify to $\mathrm{CO}, \mathrm{CH}_{4}$, or other hydrocarbons during pyrolysis (Furness et al., 2000). Likewise, during biosolids pyrolysis, nitrogen was either gasified (producing $\mathrm{N}_{2}, \mathrm{NH}_{3}$, or $\mathrm{HCN}$ ) or held within the biochar (Cao et

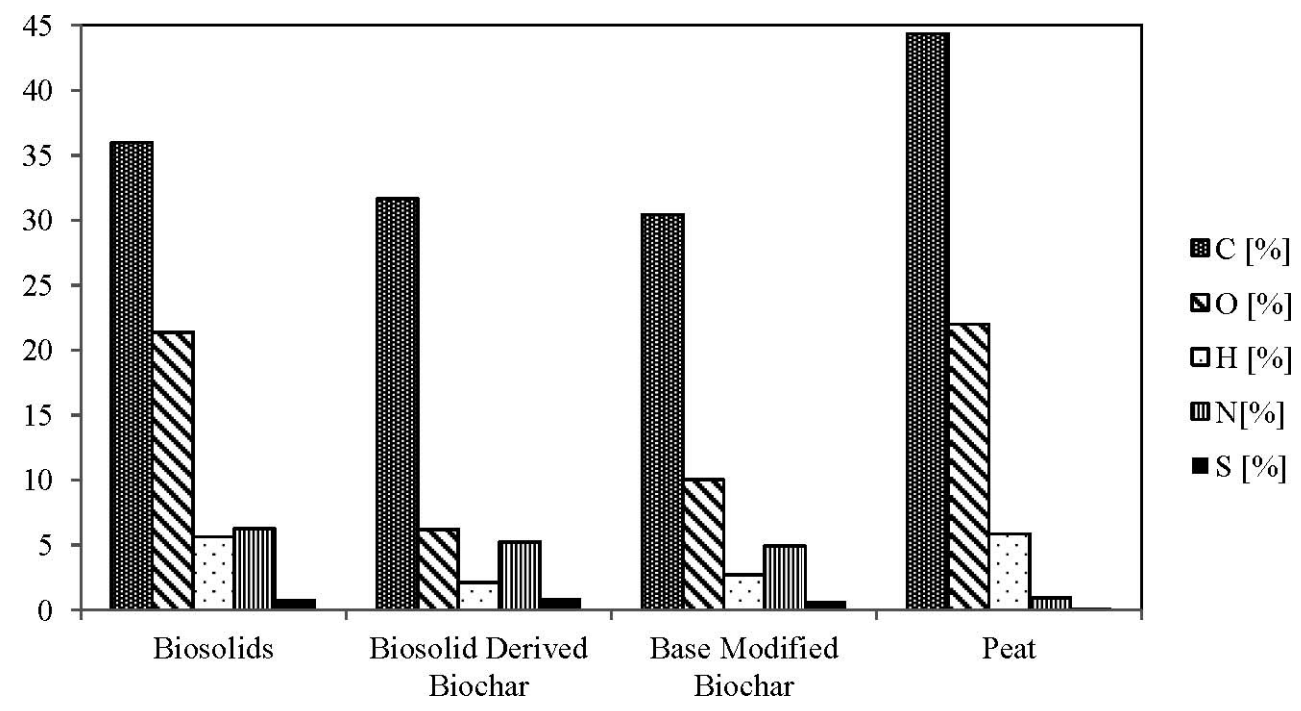

Figure 2-Results of ultimate analysis. Mass \% of most abundant molecules. 


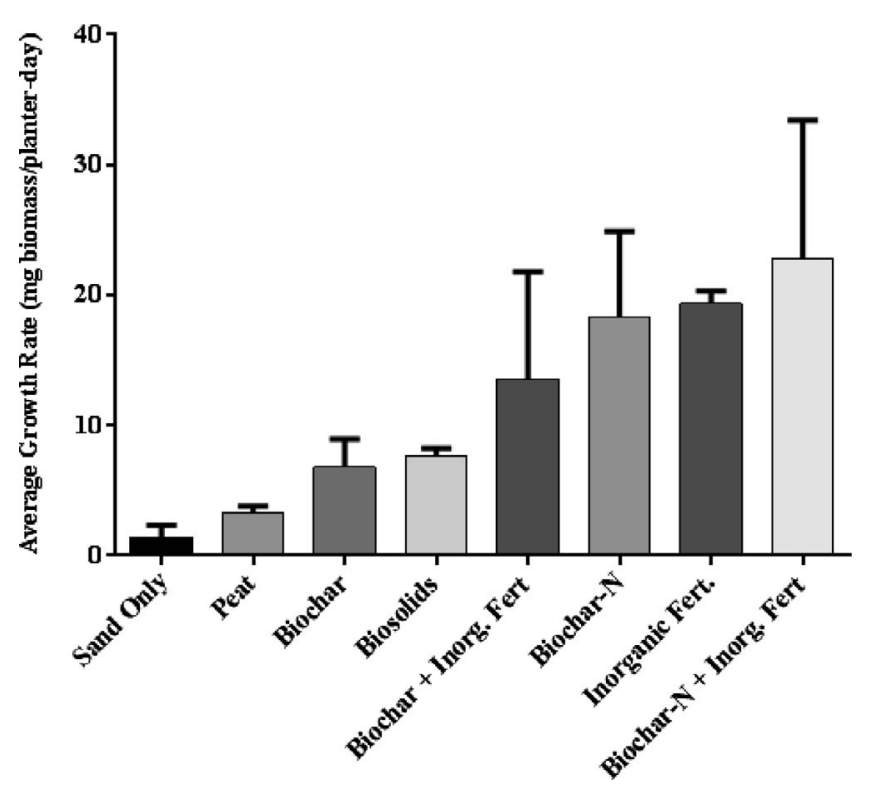

Figure 3-Average growth rate of Kentucky bluegrass biomass. Biomass was measured immediately after trimming to a height of 1 in.

al., 2013). Most of the nitrogen retained in the biochar may be strongly bonded to carbon and not readily plant available. Nitrogen may not become plant available until biochar begins to biodegrade. The half-life of biochar has been reported to be approximately 100 years in soil (Kuzyakov et al., 2014); therefore some or all of the nitrogen remaining within biochar after pyrolysis is not plant available within the season of application.

Unmodified biochar contained $14 \mathrm{mg} / \mathrm{kg}$ more $\mathrm{NH}_{3}-\mathrm{N}$ compared to base modified biochar. In precursory isotherm studies, unmodified biochar released $\mathrm{NH}_{3}-\mathrm{N}$ and did not adsorb nitrogen species from aqueous solution. Unmodified biochar was used in turfgrass growth studies because of this intrinsic release of $\mathrm{NH}_{3}-\mathrm{N}$.

Turfgrass Growth. Biochar- $\mathrm{N}$ and commercial fertilizer resulting in similar increased turfgrass growth rate (approximately $19 \mathrm{mg}$ biomass growth/d). Average growth rates were determined for each soil treatment (Figure 3). Significant differences were found between the different soil treatments based on ANOVA ( $p$-value $<0.05$ ); the treatments that were statistically different based on post analysis Fisher's least square difference are shown in Table 2. Turfgrass growth with biochar$\mathrm{N}(18.3 \mathrm{mg} / \mathrm{d})$ was significantly more rapid than the growth rates with dried biosolids $(7.7 \mathrm{mg} / \mathrm{d})$, untreated biochar $(6.8 \mathrm{mg} / \mathrm{d})$, peat $(3.2 \mathrm{mg} / \mathrm{d})$, or no amendment $(1.4 \mathrm{mg} / \mathrm{d})$. Kentucky bluegrass cultivated in soil containing biochar- $\mathrm{N}$ proliferated at a statistically similar rate as Bluegrass cultivated in soil with inorganic fertilizer; specific growth curves are shown in Figure 4. No significant increase was seen when biochar- $\mathrm{N}$ and inorganic fertilizer were used in combination compared to biochar- $\mathrm{N}$ alone. This result suggests that biochar-N provided all required macronutrients (nitrogen, phosphorus, and potassium) for grass growth. Biochar- $\mathrm{N}$, inorganic fertilizer, and biochar-N + inorganic fertilizer allowed Bluegrass to grow at a higher rate than sand alone as seen in Table 2. The addition of biochar- $\mathrm{N}$ statistically increased the maximum and average growth rates of Kentucky bluegrass by 930 and $1280 \%$, respectively, in comparison to controls with only sand. Discrepancies between nutrient loading and availability existed among the various soil treatments; in general, however, it was evident that biochar-N beneficially affected turfgrass growth rate. Future studies are warranted to determine how nutrients other than nitrogen from biochar-N affect turfgrass growth.

If biochar- $\mathrm{N}$ served purely as a bulking agent, then the growth rate with biochar- $\mathrm{N}$ would be expected to be similar to growth rate observed using sand with $10 \%$ peat. However, average and maximum growth rates with biochar- $\mathrm{N}$ were significantly higher $(p$-value $<0.01)$ than growth with peat by 460 and $290 \%$, respectively. Table 3 shows the estimated nutrient loading based on plant available nutrients. The potassium provided by the biochar- $\mathrm{N}$ and inorganic fertilizer may have positively affected the grass growth as seen by the large discrepancy in the loading. Peat and biochar- $\mathrm{N}$ were applied in similar volumes; however, the amount of potassium delivered by biochar- $\mathrm{N}$ was approximately 2300 times higher than by peat. Both delivered nitrogen and phosphorus within the same order of magnitude. The loading rates for plant available nitrogen were within two orders of magnitude for biochar- $\mathrm{N}(2.47 \mathrm{mg} \mathrm{N} /$ planter$)$ and biosolids $(0.34 \mathrm{mg} \mathrm{N} /$ planter); however the loading rates for plant available potassium was disproportionately higher for planters that received plant biochar- $\mathrm{N}$ (230 $\mathrm{mg} \mathrm{K} /$ planter) compared to those that received biosolids $(0.46 \mathrm{mg} \mathrm{K} /$ planter $)$. The disproportionate loading of plant available potassium could be responsible for the increased growth rate in planters that received biochar- $\mathrm{N}$ or inorganic fertilizer in comparison to planters receiving biosolids. Potassium delivered by inorganic fertilizer and biochar-N werte within the same order of magnitude. Sandy soil typically lacks potassium, and potassium addition often stimulates early grass development.

Table 2-p-value in Fisher's least square difference between soil treatments.

\begin{tabular}{|c|c|c|c|c|c|c|c|}
\hline & Biochar-N + Inorg. fert. & Inorg. fert. & Biochar-N & Biochar + Inorg. fert. & Biosolids & Biochar & Peat \\
\hline Sand only & $0.00^{\mathrm{a}}$ & $0.00^{\mathrm{a}}$ & $0.00^{\mathrm{a}}$ & $0.01^{\mathrm{a}}$ & 0.18 & 0.25 & 0.69 \\
\hline Peat & $0.00^{\mathrm{a}}$ & $0.00^{\mathrm{a}}$ & $0.00^{\mathrm{a}}$ & $0.03^{\mathrm{a}}$ & 0.33 & 0.44 & \\
\hline Biochar & $0.00^{\mathrm{a}}$ & $0.01^{\mathrm{a}}$ & $0.02^{\mathrm{a}}$ & 0.15 & 0.84 & & \\
\hline Biosolids & $0.00^{\mathrm{a}}$ & $0.02^{\mathrm{a}}$ & $0.03^{\mathrm{a}}$ & 0.20 & & & \\
\hline Biochar + inorg. fert. & 0.06 & 0.21 & 0.30 & & & & \\
\hline Biochar-N & 0.33 & 0.81 & & & & & \\
\hline Inorg. fert. & 0.45 & & & & & & \\
\hline
\end{tabular}

Inorg. fert. = inorganic fertilizer.

${ }^{a} p$-values below 0.05 represent statistically different growth rates between groups. 


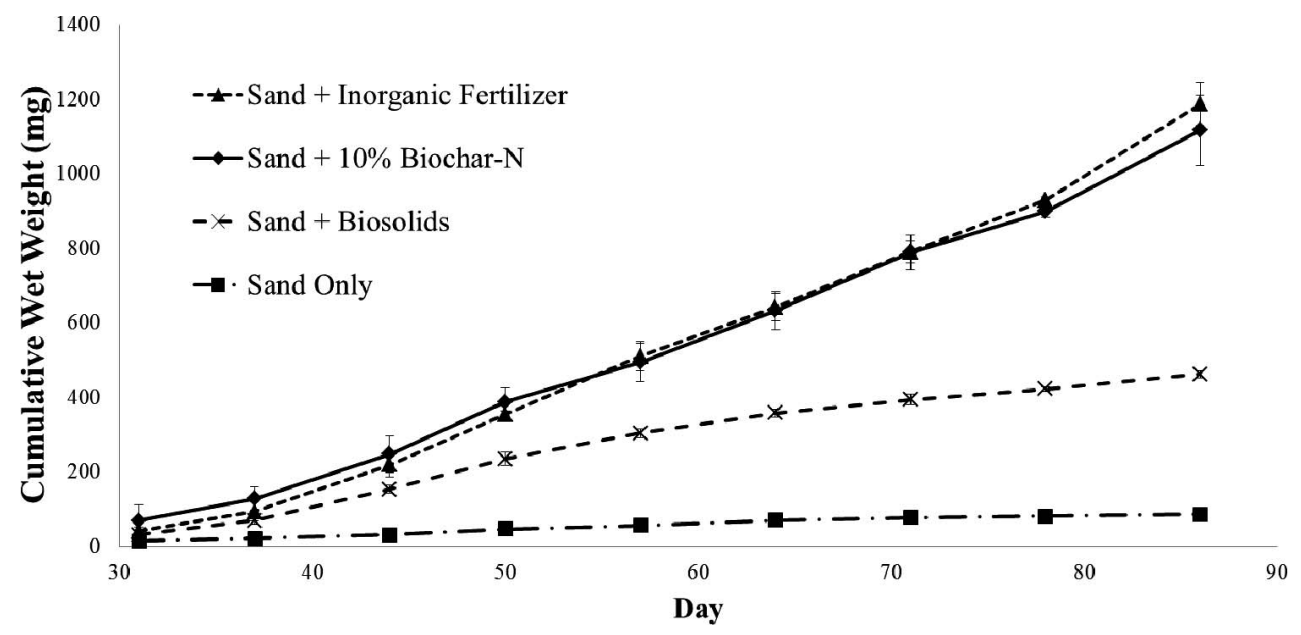

Figure 4-Cumulative weight of fresh cut Kentucky bluegrass from greenhouse study. Error bars on each point represent \pm 1 standard deviation of the biomass collected that day (some error bars hidden by point symbols).

When used together with inorganic fertilizer, unmodified biochar statistically reduced the growth rate of Kentucky bluegrass. Unmodified biochar had the same order of magnitude of nitrogen, phosphorus, and potassium as biochar-N; therefore it was expected that the addition of unmodified biochar and biochar-N may yield statistically similar growth rates; however, growth rates were statistically different (see Table 2). Given unmodified biochar + inorganic fertilizer resulted in a $40 \%$ lower average growth rate than biochar- $\mathrm{N}+$ inorganic fertilizer, unmodified biochar may contain inhibitory compounds that hinder Kentucky bluegrass germination or growth. In addition, extracts of biochar-N exhibited lower absorbance $(0.19 \pm 0.01)$ than biochar $(0.37 \pm 0.02 ; p<0.01)$ at $256 \mathrm{~nm}$, indicating that there may have been a higher $\mathrm{PAH}$ concentration in biochar compared to biochar-N (Touraud et al., 1998). The diluted extract of biochar produced at $300{ }^{\circ} \mathrm{C}\left(150{ }^{\circ} \mathrm{C}\right.$ less than the biochar used in this study) exhibited an absorbance of 3.14 ( \pm 0.55). The presence of potentially inhibitory PAHs is specific to pyrolysis temperature, and higher pyrolysis temperatures potentially produce biochars with lower PAH concentration. Further research is required to determine the effect of pyrolysis temperature on biochar PAH concentration and the subsequent effect on turfgrass growth. The highly basic solution used for surface modification or the high amount of rinsing used to wash the biochar may be responsible for removing toxic compounds, such as PAHs. Unmodified biochar and modified biochar were similar in nutrient content; however, rinsing during modification

Table 3-Nutrients delivered to planters (mg/planter).

\begin{tabular}{lccc}
\hline & $\mathbf{N}$ & $\mathbf{P}$ & $\mathbf{K}$ \\
\hline Biochar & 2.3 & 1 & 110 \\
Biochar-N $_{\text {Peat }}$ & 2.5 & 0.23 & 230 \\
Inorg. fert. $^{\text {a }}$ & 0.9 & 0.048 & 0.11 \\
Biosolids $^{\text {Biochar + inorg. fert. }}{ }^{\mathrm{a}}$ & 120 & 52 & 99 \\
Biochar-N + inorg. fert. $^{\text {a }}$ & 0.38 & 0.11 & 0.46 \\
\hline
\end{tabular}

${ }^{a}$ All inorganic (inorg.) fertilizer (fert.) was considered to be plant available. may have removed toxic compounds. Future studies should be conducted to determine the mechanisms that caused inhibition of turfgrass growth as well as pyrolysis conditions that minimize production of any products inhibitory to plant growth.

\section{Conclusions}

Biochar derived from wastewater biosolids can adsorb and carry $\mathrm{NH}_{3}-\mathrm{N}$ and potassium from wastewater streams, such as filtrate from biosolids dewatering, to soils used for plant growth. Biochar produced from digested biosolids may be a valuable agricultural product. Although there may be a complex mixture of nutrients immobilized on biochar, it was successfully demonstrated that biochar derived from biosolids can immobilize $\mathrm{NH}_{3}-\mathrm{N}$ and potassium from wastewater after washing and base activation. The $\mathrm{NH}_{3}-\mathrm{N}$ and other constituents, particularly potassium, on biochar- $\mathrm{N}$ provide favorable turfgrass growing conditions in soil. It should be noted that variability in feedstock biomass, pyrolysis conditions, and activation techniques may affect the adsorptive capacity and utility of biochar as a soil amendment. This research provides insight into a potential process for recovering $\mathrm{NH}_{3}-\mathrm{N}$ and potassium from wastewater for use in agronomy. More research is required to study the kinetics of sorption, the associated practical limitations of nitrogen removal, and application in agronomy. The potential advantages of pyrolysis for production of biochar and subsequent use as an adsorbent include energy recovery, removal of nutrients from wastewater, and production of a usable product for agronomy. Furthermore, the removal of $\mathrm{NH}_{3}-\mathrm{N}$ from biosolids dewatering filtrate/centrate in wastewater management may also reduce the ammonia loading on secondary treatment operations. Biochar produced at lower temperatures may contain constituents, such as PAHs, that inhibit turfgrass growth. Further research is required to determine optimal pyrolysis conditions for production of biochar that is beneficial to agronomy.

\section{Acknowledgments}

Funding for this project was provided by the Industry University Collaborative Research Program for Water Equip- 
ment \& Policy in Milwaukee, Wisconsin, USA, under NSF Grant Number 0968844.

Submitted for publication July 11, 2014; revised manuscript submitted January 13, 2015; accepted for publication January 15, 2015.

\section{References}

American Public Health Association (APHA); American Water Works Association; Water Environment Federation (1995) Standard Method for the Examination of Water and Wastewater, 19th ed.; American Public Health Association: Washington, D.C.; pp 4-804-81.

Asada, T.; Ohkubu, T.; Kawata, K.; Oikawa, K. (2006) Ammonia Adsorption on Bamboo Charcoal with Acid Treatment. J. Health Sci., 52 (5), 585-589.

Azargohar, R.; Dalai, A. K. (2008) Steam and KOH Activation of Biochar: Experimental and Modeling Studies. Microporous Mesopourous Mater., 110 (2-3), 413-421.

Bansode, R. R.; Losso, J. N.; Marshall, W. E.; Rao, R. M.; Portier, R. J. (2003) Adsorption of Volatile Organic Compounds by Pecan Shelland Almond Shell-Based Granular Activated Carbon. Bioresour. Technol., 90, 175-184.

Boopathy, R.; Karthikeyan, S.; Mandal, A. B.; Sekaran, G. (2013) Adsorption of Ammonium Ion by Coconut Shell-activated Carbon from Aqueous Solution: Kinetic, Isotherm, and Thermodynamic Studies. Environ. Sci. Pollut. Res., 20, 533-542.

Brockhoff, S.; Christians, N.; Killorn, R.; Horton, R.; Davis, D. (2010) Physical and Mineral-Nutrition Properties of Sand-Based Turfgrass Root Zones Amended with Biochar. Agron. J., 102 (6), 1627-1631.

Cao, J. P.; Li, L. Y.; Morishita, K.; Xiao, X. B.; Zhao, X. Y.; Wei, X. Y;; Takarada, T. (2013) Nitrogen Transformations during Fast Pyrolysis of Sewage Sludge. Fuel, 104, 1-6.

Furness, D. T.; Hoggett L. A.; Judd S. J. (2000) Thermochemical Treatment of Sewage Sludge. J. Chart. Inst. Water Environ. Res., 14, $57-65$.

Gao, X.; Wu, H. (2011) Biochar as a Fuel: 4. Emission Behavior and Characteristics of PM1 and PM10 from the Combustion of Pulverized Biochar in a Drop-Tube Furnace. Energy Fuels, 25, 2702-2710.

Gaunt, J.; Lehmann, J. (2008). Energy Balance and Emissions Associated with Biochar Sequestration and Pyrolysis Bioenergy Production. Environ. Sci. Technol., 42 (11), 4152-4158.

Inguanzo, M.; Dominguez, A.; Menedez, J. A.; Blanco, C. G.; Pis, J. J. (2002) On the Pyrolysis of Sewage Sludge: the Influence of Pyrolysis Conditions on Solid, Liquid and Gas Fractions. J. Anal. Appl. Pyrolysis, 63, 209-222.

Jiang, T. Y.; Jiang, J.; Xu, R. K.; Li, Z. (2012) Adsorption of Pb(II) on variable Charge Soils Amended with Rice-Straw Derived Biochar. Chemosphere, 89 (3), 249-256.

Kalyak, Y.; Mok-Ryun, Y.; Jae-Kyu, Y.; Yoon-Young, C. (2013) Adsorption of TNT and RDX Contaminants by Ambrosia trifida L. var trifida Derived Biochar. Res. J. Chem. Environ., 17 (4), 62-71.

Kaminsky, W.; Semel, J.; Sinn, H. (1982) Preliminary Experiments of Sewage-Sludge Pyrolysis in an Indirectly Heated Fluidized-Bed. Makromol. Chem., Rapid Commun., 3 (5), 371-375.

Kasakura, T.; Majima, T.; Izumi, N. (1981) Automatic-Control of the Sewage-Sludge Pyrolysis Process in Multiple Hearth Furnace. Water Sci. Technol., 13 (11-1), 605-610.

Kasakura, T.; Hiraoka, M. (1982) Pilot-Plant Study on Sewage-Sludge Pyrolysis. 1. Water Res., 16 (8), 1335-1348.

Lehmann, J. (2007) Bio-energy in the Black. Front. Ecol. Environ., 5 (7) 381-387.

Liu, T.; Liu, B.; Zhang, W. (2014) Nutrients and Heavy Metals in Biochar Produced by Sewage Sludge Pyrolysis: Its Application in Soil Amendment. Pol. J. Environ. Stud., 23 (1), 271-275.
Long, X. L.; Cheng, H.; Xin, Z. L.; Xiao, W. D.; Li, W.; Yuan, W. K. (2008) Adsorption of Ammonia on Activated Carbon from Aqueous Solutions. Environ. Prog., 27 (2), 225-233.

Love, C. D.; Kolar, P.; Classen, J. J.; Das, L. (2011) Adsorption of Ammonia on Ozonated Activated Carbon. Trans. ASABE, 54 (5), 1931-1940.

Ma, H.; Su, S.; Liu, H.; Yang, X.; Peng, H.; Yu, Z. (2010) Potassium Resource and Sustainable Development of Potash Salt Industry in China. Earth Sci. Front., 17, 294-310 (in Chinese).

Mayer, B. K.; Gerrity, D.; Rittmann, B. E.; Reisinger, D.; Brandt-Williams, S. (2013) Innovative Strategies to Achieve Low Total Phosphorus Concentrations in High Water Flows. Crit. Rev. Environ. Sci. Technol., 43 (4), 409-441.

McCarty, P.; Bae, J.; Kim, J. (2011) Domestic Wastewater Treatment as a Net Energy Producer-Can This Be Achieved? Environ. Sci. Technol., 45 (17), 7100-7106.

McNamara, P.; Koch, J.; Zitomer, D. (2014) Pyrolysis of Wastewater Biosolids: Lab-Scale Experiments and Modeling. Proceedings of Residuals and Biosolids 2014; Water Environment Federation: Alexandria, Virginia; 14 pp.

Metcalf \& Eddy; Tchobanoglous, G.; Burton, F. L.; Stensel, H. D. (2003) Wastewater Engineering: Treatment and Reuse, 4th ed.; McGrawHill: Boston.

Phoenix Energy (2014) Biochar from Phoenix Energy. http://www. phoenixenergy.net (accessed May 10, 2014).

Rambabua, N.; Azargohara, R.; Dalaia, A. K.; Adjayeb, J. (2013) Evaluation and Comparison of Enrichment Efficiency of Physical/ Chemical Activations and Functionalized Activated Carbons Derived from Fluid Petroleum Coke for Environmental Applications. Fuel Process. Technol., 106, 501-510

Revell, K. T.; Maguire, R. O.; Agblevor, F. A. (2012) Influence of Poultry Litter Biochar on Soil Properties and Plant Growth. Soil Sci., 177 (6), 402-408.

Schulz, H.; Glaser, B. (2012) Effects of Biochar Compared to Organic and Inorganic Fertilizers on Soil Quality and Plant Growth in a Greenhouse Experiment. J. Plant Nutr. Soil Sci., 175 (3), 410-422.

Taghizaheh-Toosi, A.; Clough, T.; Sherlock, R.; Condron, L. (2012) Biochar Adsorbed Ammonia Is Bioavailible. Plant Soil, 350, 11-25.

Touraud, E.; Crone, M.; Thomas, O. (1998). Rapid Diagnosis of Polycyclic Aromatic Hydrocarbons (PAH) in Contaminated Soils with the Use of Ultraviolet Detection. Field Anal. Chem. Technol., 2, 221-229,

U.S. Environmental Protection Agency (1998) National Strategy for the Development of Regional Nutrient Criteria; EPA-822-F-98-002; U.S. Environmental Protection Agency: Washington D.C.

Van Zwieten, L.; Kimber, S.; Downie, A.; Morris, S.; Petty, S.; Rust, J.; Chain, K. Y. (2010) A Glasshouse Study on the Interaction of Low Mineral Ach Biochar with Nitrogen in a Sandy Soil. Aust. J. Soil Res., 48, 569-576.

Verstraete, W.; Van de Caveye, P.; Diamantis, V. (2009) Maximum Use of Resources Present in Domestic "Used Water". Bioresour. Technol., 100, 5537-5545.

Vlek, P. L. G.; Kuhne, R. F.; Denich, M. (1997) Nutrient Resources for Crop Production in the Tropics. Philos. Trans.: Biol. Sci., 352, 975985.

Volli, V.; Singh, R. K. (2012) Production of Bio-Oil from De-Oiled Cakes by Thermal Pyrolysis. Fuel, 96, 579-585.

Wang, Z. H.; Chen, D. Z.; Song, X. D.; Zhao, L. (2012) Study on the Combined Sewage Sludge Pyrolysis and Gasification Process: Mass and Energy Balance. Environ. Technol., 33 (22), 2841-2488.

Woolf, D.; Amonette, J. E.; Street-Perrott, F. A.; Lehmann, J.; Joseph, S. (2010). Sustainable Biochar to Mitigate Global Climate Change. Nat. Commun., 1 (5), 56.

Xu, K. N.; Wang, C. W.; Wang, X. X.; Qian, Y. (2012) Laboratory Experiments on Simultaneous Removal of K and P from Synthetic and Real Urine for Nutrient Recycle by Crystallization of 
Magnesium-Potassium-Phosphate-Hexahydrate in a Draft Tube and Baffle Reactor. Chemosphere, 88 (2), 219-223

Yao, Y.; Gao, B.; Zhang, M.; Inyang, M.; Zimmerman, A. R. (2012) Effect of Biochar Amendment on Sorption and Leaching of Nitrate, Ammonium, and Phosphate in a Sandy Soil. Chemosphere, 89, 1467-1471.

Zhang, Z. B.; Cao, X. H.; Liang, P.; Liu, Y. H. (2013) Adsorption of Uranium from Aqueous Solution Using Biochar Produced by
Hydrothermal Carbonization. J. Radioanal. Nucl. Chem. 295 (2), 1201-1208.

Zheng, W.; Guo, M. X.; Chow, T.; Bennett, D. N.; Rajagopalan, N. (2010) Sorption Properties of Greenwaste Biochar for Two Triazine Pesticides. J. Hazard. Mater., 181 (1-3), 121-126.

Zimmerman, A. R.; Gao, B.; Ahn, M. (2011) Positive and Negative Carbon Mineralization Priming Effects Among a Variety of BiocharAmended Soils. Soil Biol. Biochem., 43, 1169-1179. 